\title{
An experimental Study of Kevlar/epoxy Composite cylinders under internal pressure loading
}

\author{
Dr. Ayad Abed Ramadhan \\ Al-Hawija Technical Institute \\ ayad_almuhndis@yahoo.com
}

\begin{abstract}
:
An experimental study of Kevlar-29/epoxy composite thin wall cylinders under internal pressure loading has been investigated in this work. Kevlar/epoxy composite specimens were fabricated and tested. Specimens were tested using the hydraulic pump and subjected to a static internal pressure. The results obtained from this work to find the pressure increase ratio and the failure load were found and a comparison has been achieved. According to the comparison results the tough material was specified. The efficient and effective composite cylinders have been tested experimentally. And this provided a considerable advantage over using a woven roving fiber in pressure vessels applications.
\end{abstract}

Keywords: Kevlar/epoxy, Composite materials and internal pressure loading

$$
\begin{aligned}
& \text { الدر اسة العملية لمركب الكفلر/ايبوكسي للاسطوانات تحث ثأثير أحمال الضغط الداخلي }
\end{aligned}
$$

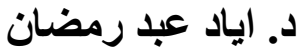

$$
\begin{aligned}
& \text { المعهد التقني الحويجة رمدان }
\end{aligned}
$$

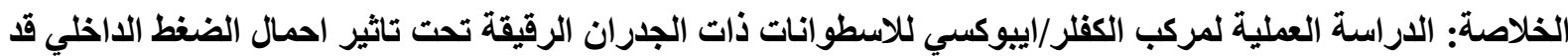

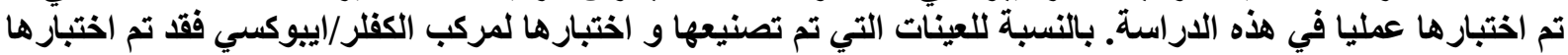

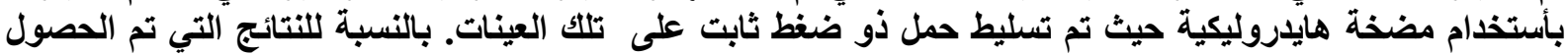

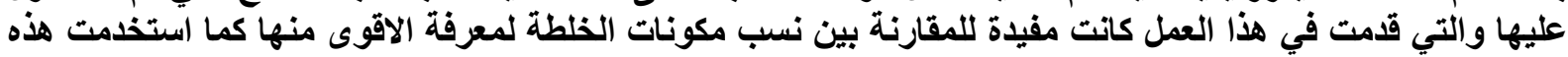

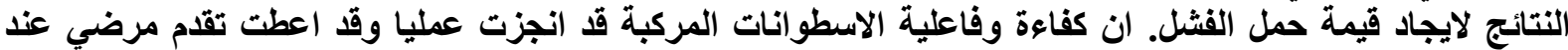
استخدام الالياف في التطبيقات التي تتعرض لإن لاحمال الضغط.

الكلمات الدالة: كفلر/ايبوكسي ، المواد المتراكبة ، حمل الضغط الداخلي 


\section{Introduction}

The ever-increasing uses of the pressure vessels can been seen widely in many industries such as ;for liquid petroleum tank, fire extinguisher, oxygen tank and power generation under unusual conditions of pressure, temperature, and environment. Therefore, it have been given a special emphasis to the analytical and the experimental methods for determining a new materials to undergo a certain high working with an appropriate safety factor and low maintenance cost [1-2]. One of the important modern materials that used in a lot of applications are the composite materials.

A great deal of attention is being concentrated on reducing the weight of pressure vessels and fuel tanks by $10 \%$ to $20 \%$. Most efforts are focused to the use of a new lighter weight and high strength materials in order to achieve this goal

Light-weight carbon fiber composite pressure vessel with inner thin-wall aluminum alloy liner has main problem of local buckling during manufacture and working process [3]. The approach of acoustic emission and Bragg grating are adapted to monitoring the light-weight composite vessel under water pressure [4]. For instance, many researchers have studied the manufacturing and designing aspects of laminated composite pressure vessels [5-6]. Recently, a number of researchers have studied the optimal design of laminated composite pressure vessels to reduce the weight and possible maintenance costs and to investigate the laminate failures. But most of these studies were about filament winding. For example, R.R. Chang [7] studied experimentally and theoretically the first- ply failure of laminated composite pressure vessels, for reliability assurance, an accurate prediction of the internal load failure process of laminated composite structures and the maximum loads that the structures can withstand before failure occurs and the effect of the number of layers on the ratio of the pressure increase, that has thus become an important topic of research. Hose and his associates [8] used a woven roving glass reinforced composite to make mixed wall pipes fabricated and subjected to an internal pressure in order to measure the strain in the inner surface.

The aim in this study to fabricate one of those composite materials that are used for the pressure vessels to make a pressure vessel that will be the most safe and more light than rest. Effect the number of composite layers on the pressure increase ratio (PIR) has been achieved in this work.

An experimental investigation of PIR in composite pressure vessel that subjected to an internal pressure load is performed using a manual pump. A comparison between the test results is made to demonstrate the suitability of the composite materials in pressure vessels fabrication.

\section{Experimental Work}

\subsection{Materials selection and specimen fabrication}

Materials selection was done after several surveys of the previous studies and thesis's recommendations that studded the composite pressure vessels that made from a reinforcement and resin. Woven roving Kevlar-29 fiber with epoxy resin (EP-A215C1) and hardener resin (EP-B215) had been selected to fabricate the composite specimens in this paper. All the specimens have the same geometry but with different numbers of fiber layers. The length of 
the specimen is $320 \mathrm{~mm}$ but the active length that consist 2, 4 and 6 layers. This specimen carry and it will carry the internal pressure load until burst. The burst normally happen in the middle of the specimen and have a length of $100 \mathrm{~mm}$ length only. The remained inactive length is in both specimen sides and it will be inside the test equipment. And this is with different geometrical shapes according to the test equipment that used in measurement and also depends on the geometrical shape. In order to make sure that the specimens will seat fit in the test equipment without any gap, the specimens geometry should be made as shown on figure 1 .

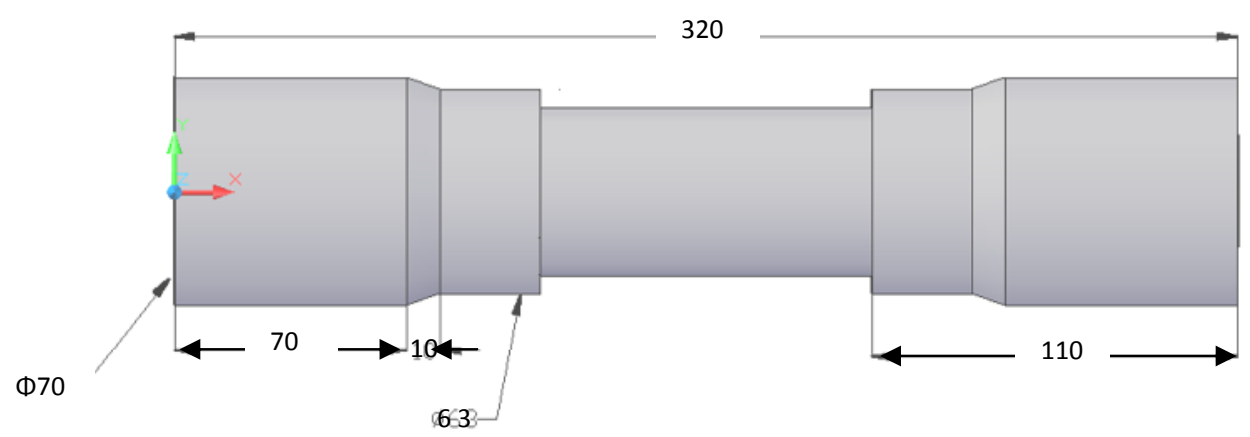

Fig 1: The geometry of the specimen (all dimensions are in $\mathrm{mm}$ )

For accuracy reasons, three specimens were fabricated having the same number of layers which means 9 specimens are required.

A comparison between the specimens that having different number of layers have been investigated. Therefore, the results are represented based on the average of the three specipnens that exposed to a same condition and as a result, 3 results will be ready for analyzing and discussion, representing all the number of layers and the kinds of the specimens.

Hand lay-up method has been used to fabricate all the specimens. Woven roving Kevlar-29 fiber is winded manually using an open mold, and epoxy resin brushed over and into the woven roving fiber. Entrapped air is removed manually with a roller as shown in Figure 2.

Finding circumference of each mandrel is the first step to specify the quantity of fiber used in this work, the length of each piece of fiber can be found by multiplying the circumference times the number of layers, then preparing all the materials, first fabrication step started with cutting woven roving fiber manually into suitable parts.

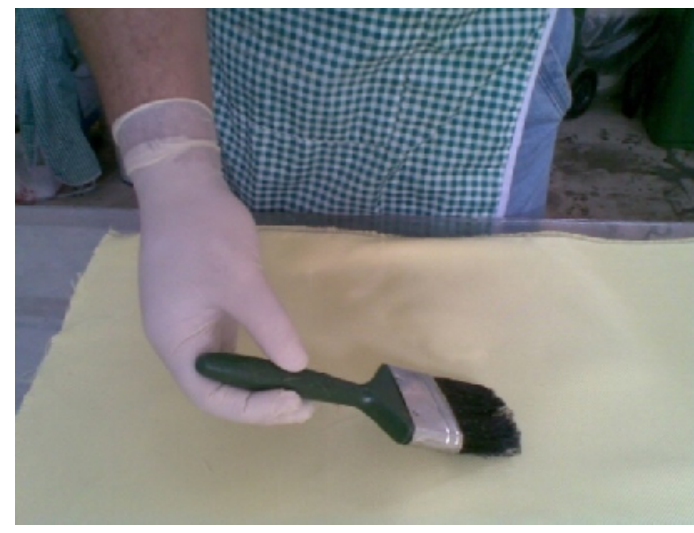

Fig 2: A Photograph show a Hand Lay-Up Process

The diameter of the mandrel is $48 \mathrm{~mm}$; the circumference of the circular cross sectional area can be obtained by multiplying the diameter by $\pi$ as shown in equation 1 :

Circumference $=\pi \times \mathrm{D}$

By multiplying the circumference by the number of layers $(\mathrm{N})$ for each category of tubes 2,4 and 6 and the length of the piece of fiber can be obtained from equation 2 : 
The length $(\mathrm{m})=$ Circumference $\times \mathrm{N}$

According to the above equation the length of the fiber can be obtained. Till this step all the pieces of woven roving fiber are ready to start fabrication. The next step is preparing the mixture 20 parts using epoxy hardener from Leco Corporation USA. This was used for the matrix per 100 parts using epoxy resin. After the mixture become ready, using a suitable brush the mixture was distributed on the fiber of the active area, rolling the fiber on the mandrel should be done in the same time to ensure a uniform distribution of the mixture between the fiber and the layers that will produce a balanced specimens and symmetrical dimensions for all parts of the specimens. The composite tube curried out at room temperature of $32 \mathrm{C}^{\mathrm{o}}$ and leaved behind for 72 hours to provide optimum blend. After finishing the fabrication processes and by using a turning machine (XL 1880) at $320 \mathrm{rpm}$ that available in the work shop, the finishing and cutting processes were done. The Final specimens of Kevlar-29/epoxy composite material are shown in Figure 3.

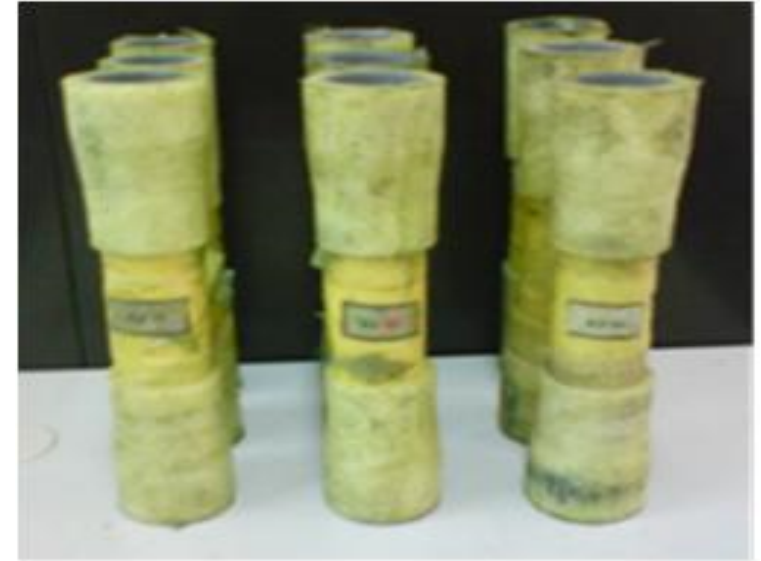

Fig 3: Typical Photograph of Kevlar29/epoxy Specimens

\subsection{Testing the Composite Tubes}

Burst pressures were measured by applying a pressurized oil to the specimens and increasing the pressure gradually until failure. At the beginning the specimen is prepared via fixing among two plugs as shown in Figure4, each plug contains three slots as a place for washers, and also each plug must be exposed to silicon glue to make it safer against leakage. Then the specimen should be fixed from both side using flanges, in order to ensure holding the plugs tightly inside the specimen during the test. Afterword connecting the pump to the specimen using a high pressure pipe, then the specimen becomes ready for test and by it above putting the specimen on a suitable stand, then pumping the oil starting manually until failure. (See Figure 5).
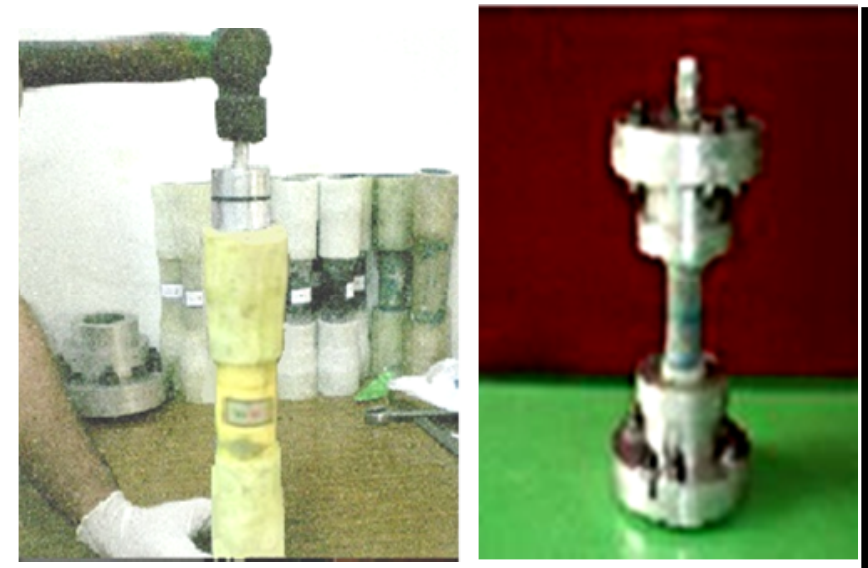

Fig. 4: Photograph show the plugs fixing process

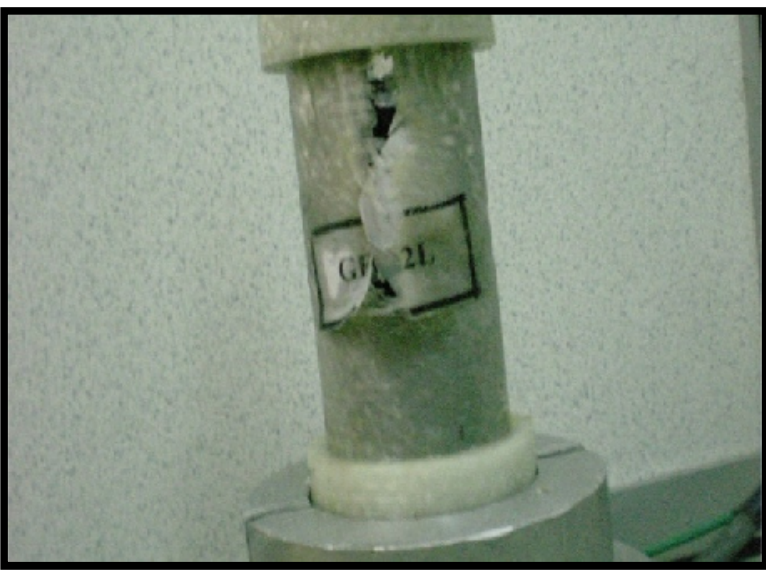

Fig. 5: The specimen after failure occurred 


\section{Results and Discussions}

The burst pressure test applied for the three specimen sets and the test results will be discussed below and according to average burst pressure for number of layers and by using composite other relations and parameters were find and discussed. To make a comparison between the maximum (burst) pressures of specimens that have been recorder, they are tested in Table 1. And they show the average values of the burst pressures for each number of layers for all the specimens

Table 1: The Burst Pressure and Average Pressure for Kevlar-29/Epoxy

\begin{tabular}{|c|c|c|c|}
\hline $\begin{array}{l}\text { No. of } \\
\text { Layers }\end{array}$ & $\begin{array}{c}\text { No. of } \\
\text { Specimens }\end{array}$ & $\begin{array}{l}\text { The Maximum } \\
\text { Pressure (bar) }\end{array}$ & $\begin{array}{c}\text { Average of Maximum } \\
\text { Pressure (bar) }\end{array}$ \\
\hline \multirow{3}{*}{2} & Specimen 1 & 91 & \multirow{3}{*}{96} \\
\hline & Specimen 2 & 97 & \\
\hline & Specimen 3 & 100 & \\
\hline \multirow{3}{*}{4} & Specimen 1 & 220 & \multirow{3}{*}{227} \\
\hline & Specimen 2 & 236 & \\
\hline & Specimen 3 & 225 & \\
\hline \multirow{3}{*}{6} & Specimen 1 & 331 & \multirow{3}{*}{339} \\
\hline & Specimen 2 & 339 & \\
\hline & Specimen 3 & 348 & \\
\hline
\end{tabular}

From table 1 above, the value of $\mathrm{P}_{\max }$ increased gradually from the lowest pressure in Kevlar29/epoxy specimens depending on the number of layers. The maximum pressure (burst pressure) is proportional to the number of layers or the thickness of the specimen wall. And also the specimens that have six layers $(6 \mathrm{~L})$ always can carry the highest $\mathrm{P}_{\max }$ and highest internal load comparing with the other specimens that made from two layers (2L) and four layers (4L).

\subsection{Pressure Increase Ratio (PIR)}

The pressure increase ratio (PIR) is the ratio between the maximum average pressures in the same type of specimens has a different number of layers. This can be obtained from the following equation (3):

$$
P R=\frac{P_{M e x(\text { (HighNo. of Layers) }}-P_{M c x \text { (LowNo. of Layes) }}}{P_{\text {Mex (LowNo. of Layers) }}}
$$

Where, $\left(\mathrm{P}_{\mathrm{Max}}\right)$ will be the average maximum pressure for different number of layers in the same type of specimens. This parameter is very important to study the behavior of composite materials in pressure vessels design when internal load is applied in of the specimens.

By applied (equation3) on the average maximum pressure that shown in Table 1, (P.I.R) for Kevlar-29/Epoxy specimens is found as a schematic diagram as shown in Figure 6 and the chart in Figure 7. 


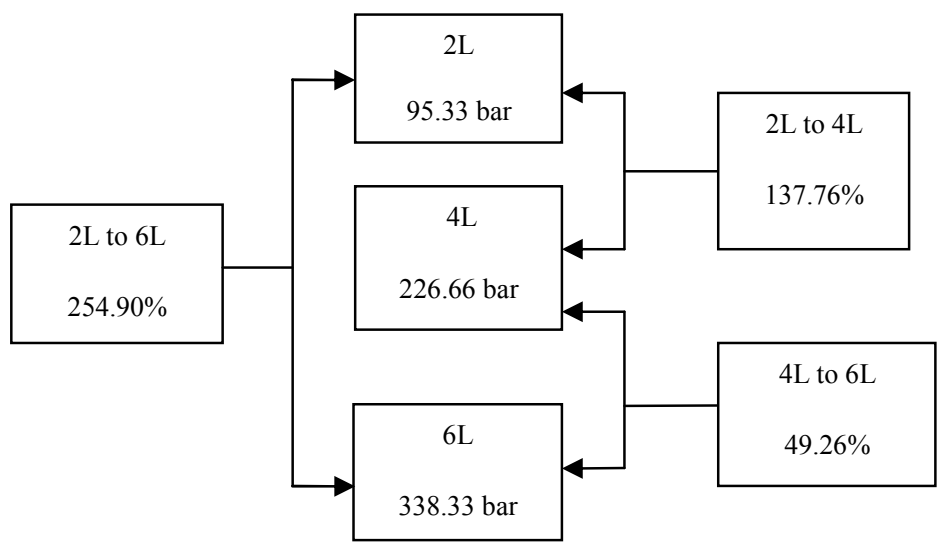

Fig 6: Schematic Diagram, Increase Ratio for KE specimens

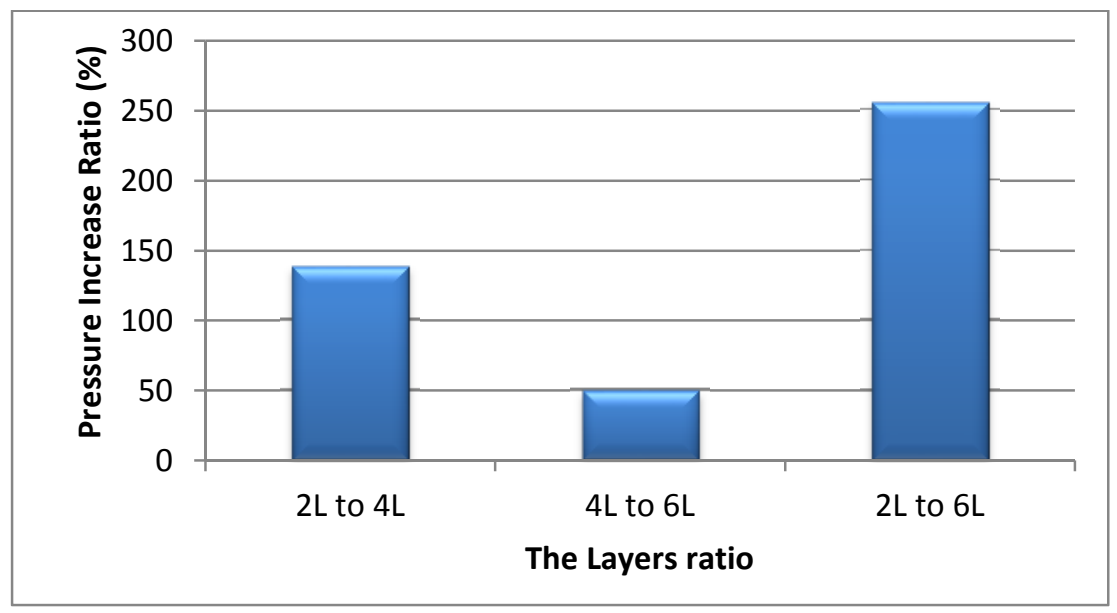

Fig 7: The Variation of Pressure Increase Ratio for KE Specimens

Figure 7 illustrates the variation of PIR in Kevlar-29/epoxy specimens between different numbers of layers, the ratio decrease from (137.76\%) in two numbers of layers to four numbers of layers into $(49.26 \%)$ between four numbers of layers to six numbers of layers that mean the total decrease is $(88.5 \%)$. While the PIR between the two numbers of layers and six numbers of layers is $(254.90 \%)$. That also means the PIR for Kevlar-29/Epoxy specimens decrease as much as the numbers of layers increase but the specimens have the best ratio of reduction in PIR that mean in any design application it requires less internal load.

The summery of pressure Increase Ratio of the result are showed in figures ( 7 and 8) according to the number of layers. The PIR for four layers to six layers it can clearly noticed that the lower gain in Kevlar-29/epoxy specimens so by increasing the number of layers in specimen it can carry more internal load for the industrial applications. The highest PIR for two layers to six layers can be noted during the test.

\section{Conclusions}

In this paper, the pressure increase ratio (PIR) of 2, 4 and 6 layers of Kevlar-29/Epoxy composite cylinders were investigated and tested under internal pressure. The PIR found is 
increased with increasing the number of layers and the maximum value obtained is $254.90 \%$ of $2 \mathrm{~L}$ to $6 \mathrm{~L}$. But the PIR of number of layers for $6 \mathrm{~L}$ to $4 \mathrm{~L}(49.26 \%)$ comparison with $4 \mathrm{~L}$ to $2 \mathrm{~L}$ $(137.76 \%)$ is decreased because the ratio of number of layers is reduced also i.e. $6 \mathrm{~L} / 4 \mathrm{~L}$ less than $4 \mathrm{~L} / 2 \mathrm{~L}$.

\section{References}

[1] John Case, Lord Chilver, Carl T.F. Ross, Strength of Materials and Structures, Fourth Edition, a member of the Hodder headline group London - Sydney Auckland co-published in north, central and south America By John Wiley \& sons inc., New York Toronto, 1999, 127139

[2] Fukunaga H, Chou TW. Simplified design techniques for laminated cylindrical pressure vessels under stiffness and strength constraints. Journal of Composite Materials, 22, 1988,1157-69.

[3] Jun-qing Zhao, Xiao-dong He ,Rong-guo Wang and Wen-bo Liu, Overall evaluation light-weight composite pressure vessel with alloy liner by acoustic emission and Bragg grating, Proc. SPIE 8694, Nondestructive Characterization for Composite Materials, 2013, 86941 U (April 11, 2013).

[3] Salah M. Ali, Experimental Study of Composite Cylinders under Internal Pressure Loading. Dissertation submitted in partial fulfillment of the requirements for the degree of master of engineering, MI: University of Malaya Press, 2009.

[4] Robert J. Setlock, Jr. Hydrostatic Pressure Retainment. A thesis presented to the faculty of Engineering and Technology, MI: Ohio University Press, 2004.

[5] Perugini P. ,Application and extension of filament winding process to general shape structures, M.Sc. Thesis in aeronautical Engineering. Roma: Universita 'La Sapienza',1990

[6] Eckold GC, A design method for filament wound GRP vessels and pipework. Composite, $1985 ; 16: 41-47$

[7] R.R. Chang, Experimental and Theoretical analyses of first-ply failure of laminated composite pressure vessels, Composite Structure, 2000;49:237-243.

[8] D. R. Hose and R. Kitching. , Glass Reinforced Composite of Mixed Wall Construction, International Journal of Pressure Vessels and Piping,1987, 27;305-323

The work was carried out at the Al-Hawija Technical Institute 